\title{
TRACKING ATMOSPHERIC BOUNDARY LAYER IN TEHRAN USING COMBINED LIDAR REMOTE SENSING AND GROUND BASE MEASUREMENTS \\ Hossein Panahifar $^{1^{*}}$ and Hamid Khalesifard ${ }^{2}$ \\ ${ }^{1,2}$ Department of Physics and Center for Research in Climate Change and Global warming, Institute for Advanced Studies in Basic Sciences, No. 444 Prof. Sobouti Blvd., Zanjan 4513766731, Iran, *h.panahifar@iasbs.ac.ir
}

\begin{abstract}
The vertical structure of the atmospheric boundary layer (ABL) has been studied by use of a depolarized LiDAR over Tehran, Iran. The boundary layer height (BLH) remains under $1 \mathrm{~km}$, and its retrieval from LiDAR have been compared with sonding measurements and meteorological model outputs. It is also shown that the wind speed and direction as well as topography lead to the persistence of air pollution in Tehran. The situation aggravate in fall and winter due to temperature inversion.
\end{abstract}

\section{INTRODUCTION}

The structural parameters of atmospheric boundary layer (ABL) such as its height (BLH) is important in weather, climate and air quality models [1-2]. Despite its importance, the BLH evolution is still poorly investigated. This is as a consequence of complex processes which happen at small temporal and spatial scales.

The BLH is usually indirectly determined from Sonding. Seidel et al recommended either the parcel method or the Richardson number (RI) are the most reliable methods to retrieve BLH from sonding [3]. The LiDAR, which used for direct determination of BLH, benefits from ability to continuous sampling of the ABL. Several methods, such as the threshold method, gradient method, and variance method, have been developed to determine BLH using LiDAR measurements [4-6].
Tehran $\left(35.5^{\circ} \mathrm{N}-35.8^{\circ} \mathrm{N}, 51.2^{\circ} \mathrm{E}-51.6^{\circ} \mathrm{E}, 1040-\right.$ $1700 \mathrm{~m}$ AMSL) is the capital of Iran with more than 12 million inhabitances. The city is the most populated city in Iran and suffering from atmospheric urban pollution. There are a few papers considering the atmospheric state of Tehran. Sabetghadam et al have shown that the changes in air quality are responsible for the long term visibility degradation [7]. Halek et al have found that the mass concentration of $\mathrm{PM}_{2.5}$ increases almost three time in the cold seasons [8]. Khlesifard et al has shown that the city also had been subjected to dust events especially in spring and summer times [9-10].

This works aims to represents LiDAR based methods to retrieve BLH over Tehran. In Section 3 LiDAR measurements for the case study 14 Dec 2014 has been described. The result compares with the sonding observations and meteorological model output. To the best of our knowledge, this is the first attempt to determine BLH by remote sensing observations for Tehran.

\section{TOPOGRAPHY, GROUND BASED MEASUREMENTS}

Figure. 1 depicts the topography of Tehran, provided by the Shuttle Radar Topography Mission (SRTM) [11]. Tehran metropolitan area is extended from Alborz Mountains at the north to the Dasht-e Kavir at the south. The LiDAR facility of IASBS $\left(35.7669^{\circ} \mathrm{N}, 51.3118^{\circ} \mathrm{E}, 1430\right.$ $\mathrm{m}$ AMSL) is located in northwest Tehran and 
has started its activity since November 2014. Data collected by this facility in combination to Radiosonding measurements (Mehrabad meteorological office) were used to investigate the boundary layer structure over the city.

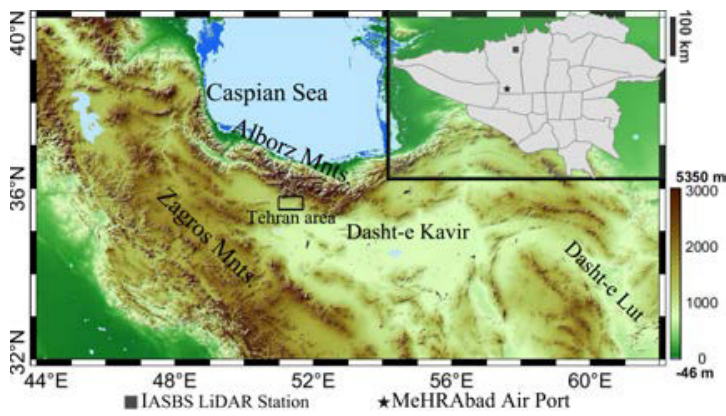

Figure 1: Topography map of Northern part of Iran provided by SRTM

The installed depolarized LiDAR benefits from a frequency doubled pulsed Nd-YAG laser with pulse duration $7 \mathrm{~ns}$, energy per pulse: $40 \mathrm{~mJ}$ @ $532 \mathrm{~nm}$ as its transmitter. On the receiver side, a sensitive polarization setup after a 8 " cassegrian telescope separate the received 532 $\mathrm{nm}$ backscattered signal to two linearly cross polarized beams. The radio-sonde $\left(35.6900^{\circ} \mathrm{N}\right.$, $51.3112^{\circ}, 1200 \mathrm{~m}$ AMSL, $\approx 8 \mathrm{~km}$ from IASBS Site) located in Mehrabad airport, and launched at a frequency of 2 times per day.

\section{RESULTS AND DISCUSSION}

Figure. 2 shows 24 hour time series for range corrected attenuated backscatter signal (RCS) on parallel channel after overlap correction. The potential temperature and relative humidity vertical profile is also shown by black and cyan line respectively. Fig. 2 very clearly depicts a nocturnal layer at early hour (00:00 till 06:00 LT) and a very stable atmosphere throughout the day. The Figure also represent development of a strong ABL due to rush-hour induced pollution (07:00 till 16:00 LT).

Figure. 3 represent the time series for depolarization signal at $532 \mathrm{~nm}$ on 14 Dec 2014.

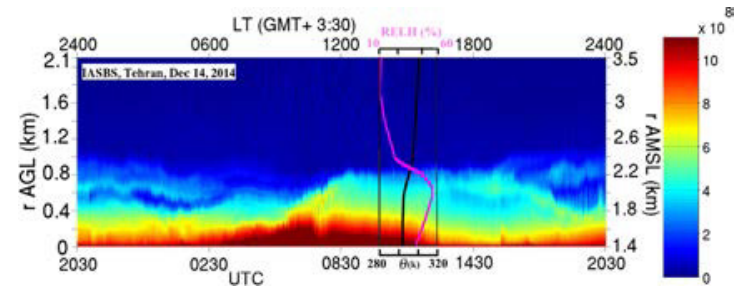

Figure 2: Time series for RCS, Potential temperature and relative humidity is shown in the box for 12:00 UTC, 14 Dec 2014

The depolarization ratio exceeds and reaches to around $25 \%$ in second half of the day. The measured values of depolarization ratio consistent with observation of smoke $(\boldsymbol{\delta} \sim 15 \%)$ and dusty mix $(\delta \sim 25 \%)$ in the atmosphere of Tehran [12].

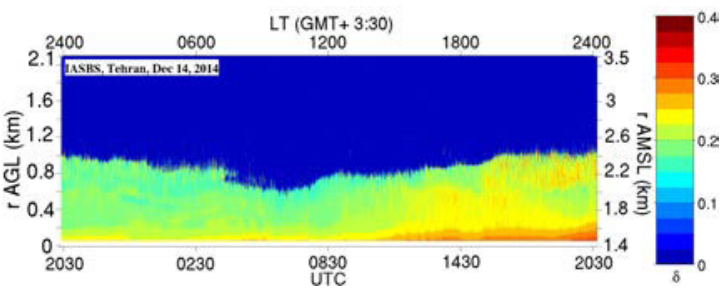

Figure 3: Time series for depolarization of LiDAR signal on 14 Dec 2014

According to HYSPLIT back trajectories (not shown) urban pollution could be the source of high $\mathrm{PM}_{2.5}$ concentration in midday and the source of dust is Dasht-e Kavir desert.

\subsection{BLH DETERMINATION WITH SONDE-LiDAR MEASUREMENTS}

For radiosonde observations, the potential temperature and wind profiles are used to estimates the BLH employing Richardson (RI) number. In this method, the height at which RI is larger than the critical value $\left(R_{i b}>R_{i b c}\right)$ is considered as BLH [4].

For LiDAR measurements, we took the following steps respectively to retrieve BLH from the range-corrected signal (RCS). Since high reso- 
lution analysis of BLH requires a high signalto-noise ratio, before any processing on RCS, an algorithm was applied to reduce the noise. The lidar profiles were also averaged over a time period $7 \mathrm{~min}$. This period corresponds to a characteristic time scale of atmospheric turbulence in the boundary layer [4]. At the next step, we took first- and second-order derivative of averaged RCS with respect to the altitude to find points at which the sign of derivatives changes. For accurate detection of BLH in the case of multiple aerosol layer (Fig. 2), we considered a threshold level. The threshold value was chosen based on the analysis of several cases.

Figure. 4 illustrates the evolution of BLH for case study 14 Dec 2014. The red line identifies the BLH as determined through LiDAR approach.

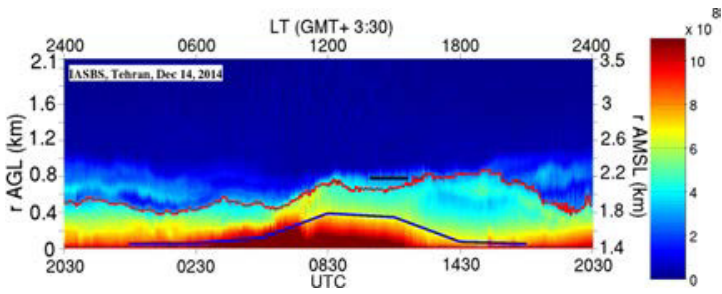

Figure 4: BLH evolution on 14 Dec 2014. The red, blue and black lines shows BLH obtained from LiDAR, NOAA model and RI.

The blue line represents the estimates obtained from NOAA HYSPLIT transport and dispersion model (GDAS 1). The black vertical line shows the BLH obtained from RI method for radiosonde launched at 12:00 UTC on Mehrabad airport. The figure covers the complete diurnal cycle of the BLH evolution. The BLH is found to grow during the day, reaching a maximum value in the early afternoon and then decaying in the late afternoon and evening (with respect to LT). Since we benefit from a high power output LiDAR with spatial resolution $\sim 15 \mathrm{~m}$, so we also could retrieved the depth of entrainment zone precisely.

\section{CONCLUSIONS}

In this study, the BLH which is determined from three distinct approaches have compared for case study 14 Dec 2014 (Fig. 4). The LiDAR approach considers a method based on the identification of minima in the first- and second-order derivative of the RCS. We took a minimum which exceeds from specific threshold as the BLH. Additional estimates of the BLH are obtained from radiosonde observation and NOAA HYSPLIT meteorological model. Looking to Fig. 4, One can easily find that the differences of BLH retrieved from LiDAR and sonding observations are less than a hundred meters. While there is a considerable differences between the BLH obtained from NOAA HYSPLIT meteorological model and two other approaches.

Figure. 5 depictes average wind speed and directions for healthy (According to Tehran Air Quality Control Company) and Un-healthy days on a period of 5 years for Mehrabad airport. The majority of surface winds blows from the south when air is at unhealthy condition. On the other hand, at days with good air quality condition, the surface winds have more west-east component. So it seems that Alborz Mountain inhibit ventilation of pollutants and blocked northerly wind blowing from south. The wind speed almost remains below 3 $\mathrm{m} / \mathrm{se}$ for unhealthy days.

Therefore, Topography as well as wind speed and direction, and temperature inversion could be considered as the main factors which lead to urban pollution in Tehran. The BLH also remain under $1 \mathrm{~km}$ especially in cold seasons.

\section{ACKNOWLEDGEMENTS}

The authors would like to express their gratitude to Ruhollah Moradhaseli for valuable discussions. The authors gratefully acknowledge the NOAA Air Resources Laboratory (ARL) 


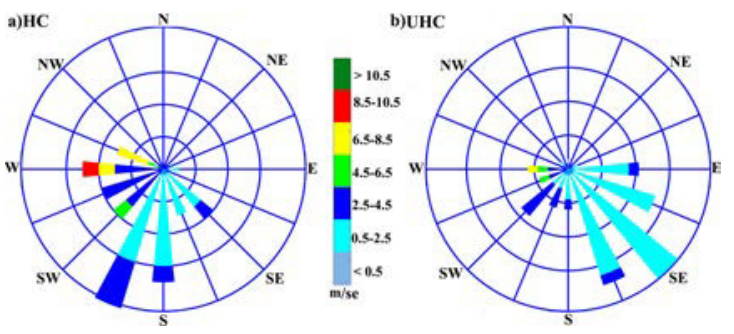

Figure 5: Windrose over Mehrabad airport over 5 year period a) Days with healthy condition $(H C) b$ ) Days with unhealthy condition (UHC)

for the provision of the HYSPLIT transport and dispersion model used in this work. Special thanks go to Larry Oolman for kindly providing some of the surface observations.

\section{References}

[1] Stull, R. B.: An Introduction to Boundary Layer Meteorology, Kluwer Academic Publishers, Norwell, MA, 1988.

[2] Zilitinkevich, S. S.: The Height of the Atmospheric Planetary Boundary layer: State of the Art and New Development. National Security and Human Health Implications of Climate Change, Springer Netherlands, 147161, 2012.

[3] Seidel, D. J., Ao, C. O., and Li, K.: Estimating Climatological Planetary Boundary Layer Heights from Radiosonde Observations: Comparison of Methods and Uncertainty Analysis, J. Geophys. Res., 115, D16113, doi:10.1029/2009JD013680, 2010.

[4] Flamant, C., Pelon, J., Flamant, P. H., and Durand, P.: Lidar Determination of the Entrainment Zone Thickness at the Top of the Unstable Marine Atmospheric Boundary Layer, Bound.-Lay. Meteorol., 83, 247284, 1997.

[5] Emeis, S., Schafer, K., and Munkel, C.: Surface-based Remote Sensing of the Mixing-layer Height-a Review, Meteorol. Z., 17,621630, 2008 .

[6] Haeffelin, M., Angelini, F., Morille, Y., Martucci, G., Frey, S., Gobbi, G. P., Lolli, S.,
ODowd, C. D., Sauvage, L., Xueref Remy, I., Wastine, B., and Feist, D. G.: Evaluation of Mixing Height Retrievals from $\mathrm{Au}-$ tomatic Profiling Lidars and Ceilometers in View of Future Integrated Networks in Europe, Bound.-Lay. Meteorol. , 143, 4975, 2012.

[7] Samaneh Sabetghadam, Farhang AhmadiGivi, Yahya Golestani, "Visibility trends in Tehran during 1958-2008", Atmos. Env. 62, 512-520 (2012).

[8] Halek, Farah, Mansour Kianpour-Rad, and Ali Kavousirahim. "Seasonal variation in ambient PM mass and number concentrations (case study: Tehran, Iran)." Environmental monitoring and assessment 169.1 (2010): 501-507.

[9] H. R. Khalesifard and H. Panahifar, "Monitoring Atmospheric Particulate Matters in Tehran by Synergy of LiDAR Measurement, Atmospheric Models and Satellite Data," in Light, Energy and the Environment 2015, OSA Technical Digest (online) (Optical Society of America, 2015), paper EM4A.1.

[10] Abdi Vishkaee, F., C. Flamant, J. Cuesta, L. Oolman, P. Flamant, and H. R. Khalesifard (2012), Dust transport over Iraq and northwest Iran associated with winter Shamal: A case study, J. Geophys. Res., 117, D03201, doi:10.1029/2011JD016339.

[11] USGS (2004), Shuttle Radar Topography Mission, 1 Arc Second scene SRTMu03n008e004, Unfilled Unfinished 2.0, Global Land Cover Facility, University of Maryland, College Park, Maryland, February 2000.

[12] Burton, S. P., Ferrare, R. A., Hostetler, C. A., Hair, J. W., Rogers, R. R., Obland, M. D., Butler, C. F., Cook, A. L., Harper, D. B., and Froyd, K. D.: Aerosol classification using airborne High Spectral Resolution Lidar measurements methodology and examples, Atmos. Meas. Tech., 5, 73-98, doi:10.5194/amt5-73-2012, 2012. 